\title{
Pain Relieving Benefits of Massage Therapy Compared to Massage Therapy Combined with Microcurrent Point Stimulation
}

\author{
K Armstrong*, Antoine Chevalier, W Todorsky, Joe Durant and M Dwyer \\ International Author \& Speaker, Advocate for Health \& Healing, USA
}

Submission: February 28, 2018; Published: May 01, 2018

*Corresponding author: Kelly Armstrong, International Author \& Speaker, Advocate for Health \& Healing, 216 Baracoa Court, St. Augustine, Florida 32086, USA, Email: k.armstrongot@gmail.com

\begin{abstract}
Objectives: Although massage and microcurrent are widely used for chronic pain, there remains considerable controversy as to their therapeutic value for back pain. We aimed to determine the effect size of both massage and microcurrent therapy applied to lower back acupuncture points to assess their impact on chronic pain.

Design: This was cohort analysis of treatment outcomes pre and post massage and pre-post massage combined with microcurrent point stimulation. Two patient sample groups of 49 patients with a history of non-specific chronic pain were studied.

Interventions: Massage therapy alone was applied for 1 hour in the massage sample group. DC Microcurrent Point stimulation (MPS) was applied to a Standardized Acupuncture Protocol prior to massage therapy in the second sample group. Evaluations entailed a baseline VAS (VAS) pain scale assessment, which was repeated after massage and massage combined with MPS. All 49 patients in each sample group received either one (1) Massage Therapy or one (1) Massage and MPS session.

Outcome Measures: The VAS response of a $\mathrm{N}=49$ patient sample with chronic pain applied with Massage Therapy alone reflected a statistically significant reduction of 3.761 points or $66 \%$ reduction in mean pain levels post massage treatment, when compared to initial pain levels [95\% CI $(3.143,4.379) ; \mathrm{p}=0.000]$. There was statistically significant increase in pain of 1.293 points or $66 \%$ at the 48 hours follow-up, for a total statistically significant reduction of 2.467 points or $43 \%$ reduction in mean at the 48 hours. Massage combined with MPS provided significant reduction of 5.755 points or $75 \%$ reduction in mean pain levels post massage treatment, when compared to initial pain levels [95\% CI $(5.284,6.226)$, with a statistically insignificant increase of 0.429 points or $11 \%$ increase in mean at the 48 hours follow-up [ $95 \%$ CI $(-0.710$, -0.147 ); $\mathrm{p}=0.004$ ], for a total statistically significant reduction of 5.327 points or $78 \%$ reduction in mean at the 48 hours follow-up [ $95 \% \mathrm{CI}$ (4.842, 5.811); $\mathrm{p}=0.000]$.
\end{abstract}

Conclusion: The positive results in this study could have applications for massage therapists who treat chronic pain patients.

Keywords: Massage; Microcurrent point stimulation; Chronic pain; Standard protocol

\section{Introduction}

Chronic pain (CP) seriously affects the patient's daily activities and quality of life. Chronic pain is an epidemic worldwide, with 1.5 billion people feeling its effects. In the United States, about 100 million individuals are estimated to suffer from chronic pain, costing the country billions of dollars in health care and lost work productivity each year [1-3]. Massage, is the manipulation and kneading of muscles and joints of the body with the hands, especially to relieve tension or pain. Massage has been practiced for thousands of years and is commonly used for many types of chronic pain $[4,5]$.

Acupuncture, a physical intervention which involves placement of small needles in the skin at different acupoints, has also been practiced for thousands of years and is commonly used for many types of chronic pain [6-9]. It is believed that acupuncture relieves pain by regulating the autonomic nervous system $[10,11]$.

Microcurrent therapies involve applying weak direct currents $(80 \mu \mathrm{A}-1 \mathrm{~mA})$, and are now being increasingly recognized as an adjunct for pain relief and autonomic nervous system regulation [12-19]. There is no consensus in the literature identifying the best practice measures for enhancing outcomes in massage therapy for chronic pain patients. Although sufficient, but limited evidence supports the application of massage for chronic pain, there is limited evidence in literature to support the integration of massage and electro-therapies to do the same. The purpose of this pilot study is to compare the impact of massage therapy alone and massage therapy when combined with Microcurrent Point stimulation (MPS) on the pain levels of a two $\mathrm{N}=49$ samples of chronic pain patients, after single application. 


\section{Patients, Materials and Methodology}

This study entailed the application of manual massage to 49 chronic pain patients with a mean age of 48.62 years (SD 15.841) and suffering a mean average of 3.96 years (SD 4.780). There were 35 female and 14 male subjects in the massage sample.

This study then entailed the application of manual massage and MPS applied to standard protocol to 49 chronic pain patients with an mean age of 47.82 years (SD 11.31) suffering a mean average of 5.327 years (SD 5.6327). There were 38 female and 11 male subjects in the massage-mps sample. All patients presented to us for therapy of their problem. Inclusion criteria were simple: Massage therapists who assisted in data collection were asked to select patients who were currently suffering from chronic pain with a recorded $>2.0$ VAS Pain Scale score. The diagnoses of pain, location, severity, sex, previous interventions or surgeries were not considered exclusion criteria. Informed consent was obtained to partake in treatment and the study assessments.
Patient pain scores were recorded immediate pre treatment and twice post treatment: immediately after application, and again two days later.

Massage therapy sessions lasted 1 hour and were applied by experienced and licensed Massage Therapists with a minimum 7 years clinical practice in soft tissue pain therapy. The massage and massage-MPS sessions lasted 1 hour, with MPS applied for approximately 15 minutes prior to 45 minutes of massage therapy. Microcurrent Point stimulation (MPS) was applied by Massage therapists to Standard Protocol which included the following 20 points (Figure 1) located in the lower back, hips and legs. Device was set to negative polarity (-) and application time was 30 seconds per point. MPS was applied using Dolphin Neurostim (Center for Pain \& Stress Research, Ontario, Canada) device [20]. This is an FDA-approved device which apply low frequency, concentrated, microcurrent stimulation (at $10 \mathrm{~K}$ ohms) for the relief of chronic pain [20,21].

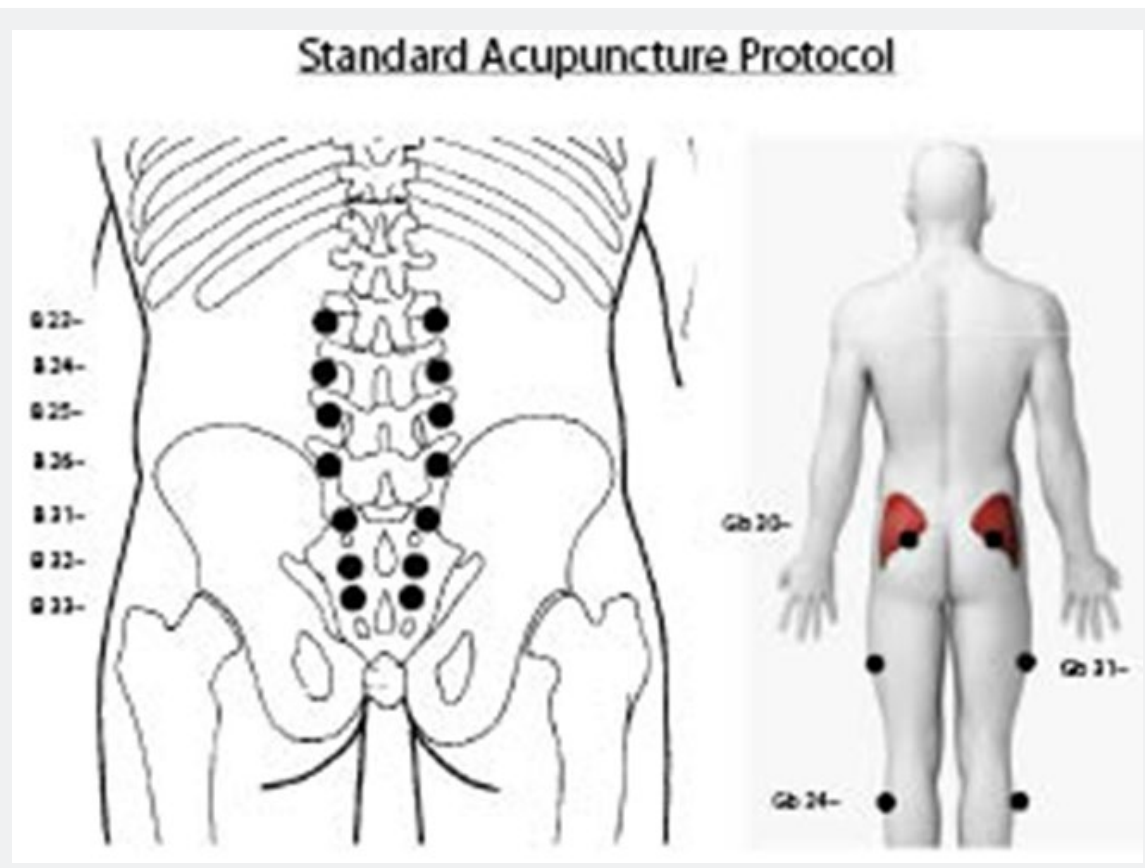

Figure 1: Standard protocol acupuncture points.

Visual Analogue Scale (VAS) was used to evaluate the patient's pain. The VAS is an 11-point scale from $0-10$ with 0 being no pain and 10 being the most intense pain imaginable.

$[22,23]$. The patient verbally selects a value that is most in line with the intensity of the pain that they have experienced in the last 24 hours or is often reported as a rating during a specific movement pattern or functional task. The VAS has good sensitivity [24] and excellent test-retest reliability [25].

Standard protocol was developed by Dr Bruce Fashong, as treatment approach to provide a simple, easy to apply, nonpharmaceutical solution for the treatment of chronic pain. The protocol involves the application of concentrated microcurrent stimulation to acupuncture points located in the paraspinal lumbar, hips and legs, that isolate the key nerves and muscles that influence core of the body. When these points (Figure 1) are collectively treated with concentrated microcurrent, it has been reported that a wide variety of neuromyofascial pain syndromes can be effectively relieved in a timely basis [15-16] (Figure 1).

The aim of this cohort preliminary study was to evaluate whether

1. Massage Therapy and/or Massage Therapy-MPS can modulate VAS pain scale in patients suffering with chronic pain.

2. Microcurrent Point stimulation when applied to STANDARD PROTOCOL and combined with Massage Therapy can further modulate or improve VAS pain scale in patients suffering with chronic pain. 


\section{Results}

The VAS response of a $\mathrm{N}=49$ patient sample with chronic pain applied with Massage Therapy alone reflected a statistically significant reduction of 3.761 points or $66 \%$ reduction in mean pain levels post massage treatment, when compared to initial pain levels [ $95 \%$ CI $(3.143,4.379) ; p=0.000]$. The was statistically significant increase in pain of 1.293 points or $66 \%$ at the 48 hours follow-up, for a total statistically significant reduction of 2.467 points or $43 \%$ reduction in mean at the 48 hours (Table 1 ).

Table 1: Massage $\mathrm{N}=49$ descriptive statistics.
Massage combined with MPS provided significant reduction of 5.755 points or $75 \%$ reduction in mean pain levels post massage treatment, when compared to initial pain levels [95\% CI $(5,284$, 6.226 ), with a statistically insignificant increase of 0.429 points or $11 \%$ increase in mean at the 48 hours follow-up [95\% CI $(-0.710,-0.147) ; p=0.004]$, for a total statistically significant reduction of 5.327 points or $78 \%$ reduction in mean at the 48 hours follow-up [95\% CI $(4.842,5.811) ; \mathrm{p}=0.000]$ (Table 2).

\begin{tabular}{|c|c|c|c|c|c|c|}
\hline & Minimum & Maximum & Mean & Std. Deviation & $\begin{array}{c}\text { Percentage\% } \\
\text { Improvement }\end{array}$ & $\begin{array}{c}\text { Confidence Interval } \\
\text { (>=95\% CI) }\end{array}$ \\
\hline Age & 15 & 79 & 48.63 & 15.841 & & \\
\hline Duration of Pain years) & 0 & 16 & 3.96 & 4.780 & & \\
\hline Initial Pain (0-10) & 2 & 10 & 5.72 & 2.131 & & \\
\hline $\begin{array}{c}\text { Post Massage Pain } \\
(0-10)\end{array}$ & 0 & 5 & 1.96 & 1.349 & $-66 \%$ & $P=0.000$ \\
\hline $\begin{array}{c}\text { Post 48hr Massage Pain } \\
(0-10)\end{array}$ & 0 & 8 & 3.25 & 2.233 & $(+66 \%)$ & $P=0.000$ \\
\hline Total Pain Relief & & & & & $-43 \%$ & $P=0.000$ \\
\hline
\end{tabular}

Table 2: Massage and SP N=49 descriptive statistics.

\begin{tabular}{|c|c|c|c|c|c|c|}
\hline & Minimum & Maximum & Mean & Std. Deviation & $\begin{array}{c}\text { Percentage\% } \\
\text { Improvement }\end{array}$ & $\begin{array}{c}\text { Confidence Interval } \\
(>=95 \% \text { CI })\end{array}$ \\
\hline Age & 18 & 75 & 47.53 & 11.310 & & \\
\hline Duration of Pain years) & .1600 & 20.0000 & 5.327755 & 5.2367226 & & \\
\hline Initial Pain & & & & & & \\
\hline$(0-10)$ & 2 & 9 & 6.94 & 1.506 & & \\
\hline Post MPS & & & & & & \\
\hline Massage Pain (0-10) & 0 & 5 & 1.61 & 1.441 & $-75 \%$ & $P=0.000$ \\
\hline $\begin{array}{c}\text { Post 48hr MPS-Massage } \\
\text { Pain (0-10) }\end{array}$ & 0 & 3 & 1.18 & 1.054 & $-11 \%$ & $\mathrm{P}=0.004$ \\
\hline \begin{tabular}{c} 
Total Pain Relief \\
\hline
\end{tabular} & & & & & $-78 \%$ & $P=0.000$ \\
\hline
\end{tabular}

\section{Discussion}

Chronic pain affects millions of people every year and the effects of pain result in tremendous health care costs, in terms of rehabilitation and lost worker productivity, plus the emotional and financial burden it places on patients and their families. Application of Massage Therapy to chronic pain patients produced a respectable $66 \%$ pain relief post treatment. Lasting results were not realized as pain outcomes dropped to $43 \% 48$ hours later. However, these outcomes are still consistent with both acupuncture and physiotherapy, which report an average reduction of $40-50 \%$ in mean pain scores $[26,27]$.

Microcurrent Point stimulation applied to Standard Protocol prior to massage therapy provided a marked improvement in pain outcomes over massage therapy alone both post application ( $66 \%$ vs $75 \%$ ), and the 48 hourfollow-up ( $43 \%$ vs $78 \%$ ). The consistency of chronic pain outcomes improved with the combination of MPS applied to standard protocol prior to the massage suggests there is strong neurological relationship between stress and chronic pain of the body.

It is suggested that low-frequency DC microcurrent may activate release of endorphins from the pituitary [28]. It is further suggested that DC microcurrent mimics human bio-cellular communications, regulating the autonomic nervous system, resulting in body wide therapeutic benefits $[12,14,17,19]$. Both these biochemical processes may provide a plausible explanation for the improved prolonged pain relief after combining DC microcurrent with massage therapy, and is an area where future research is required. We have previously reported, in several published studies, reduction in pain, sympathetic stress and cortisol with improvements in autonomic nervous system regulation in patients using MPS [14-18]. It is possible that this same mechanism of action is at play in this cohort analysis, as many of the locations of chronic pain locations were different from the MPS application site (Table 3): this has to be confirmed in additional patient studies. 
Table 3: Descriptive statistics.

\begin{tabular}{|c|c|c|c|c|c|}
\hline $\begin{array}{l}\mathrm{N}=49 \text { Massage } \\
\text { Pain Location }\end{array}$ & Total & Percentage \% & $\begin{array}{l}\mathrm{N}=49 \text { Massage }+ \\
\text { MPS Pain Location }\end{array}$ & Total & Percentage $\%$ \\
\hline Back & 25 & $51 \%$ & Back & 25 & $51 \%$ \\
\hline Neck & 7 & $16 \%$ & Shoulder & 7 & $16 \%$ \\
\hline Hip & 5 & $10 \%$ & Knee & 4 & $9.0 \%$ \\
\hline Shoulder & 4 & $9.0 \%$ & Hip & 3 & $6.0 \%$ \\
\hline Abdomen & 3 & $6.0 \%$ & Neck & 3 & $6.0 \%$ \\
\hline Knee & 2 & $4.0 \%$ & Post Polio & 1 & $2.0 \%$ \\
\hline Leg & 1 & $2.0 \%$ & Leg & 1 & $2.0 \%$ \\
\hline RSD & 1 & $2.0 \%$ & Pelvis & 1 & $2.0 \%$ \\
\hline \multirow[t]{3}{*}{ Total } & 49 & $100 \%$ & Carpal Tunnel & 1 & $2.0 \%$ \\
\hline & & & Neuropathy & 1 & $2.0 \%$ \\
\hline & & & Total & 49 & $100 \%$ \\
\hline
\end{tabular}

Massage N=49 Pain Location, Massage/MPS N=49 Pain Location.

\section{Conclusion}

Chronic back pain can limit quality of life, restrict work and social engagement, and is often blamed for the development of drug dependency of various forms. This study showed Massage Therapy provided statistically significant $43 \%$ improvement $(\mathrm{p}<=0.0001)$ in patient pain levels 48 hours after initial treatment. When MPS was combined with Massage therapy, a further statistically significant $78 \%(\mathrm{p}<=0.0001)$ pain relief was recorded 48 hours later. These significant improved changes help validate the potential application of MPS to STANDARD PROTOCOL as an viable option to Massage therapists treating patients with related chronic pain. However, long term further investigation is warranted with a larger focus group to confirm these results and to assess their duration.

\section{References}

1. Committee on Advancing Pain Research, Care, and Education (2011) Relieving pain in America: A Blueprint for transforming prevention, care, education, and research. Institute of Medicine of the National Academies, Washington, DC, USA.

2. Relieving Pain in America (2011) A Blueprint for Transforming Prevention, Care, Education, and Research. Institute of Medicine (US) Committee on Advancing Pain Research, Care, and Education. National Academies Press, Washington, DC, USA.

3. Gaskin DJ, Richard P (2012) The economic costs of pain in the United States. J Pain 13(8): 715-724.

4. Tsao JC (2007) Effectiveness of Massage Therapy for Chronic, Nonmalignant Pain: A Review. Evid Based Complement Alternat Med 4(2): 165-179.

5. Furlan A, Imamura M, Dryden T, Irvin E (2009) Massage for low back pain: An updated systematic review within the framework of the Cochrane Back Review Group. Spine 34(16): 1669-1684.

6. Vickers AJ, Cronin AM, Maschino AC, Lewith G, MacPherson H, et al. (2012) Acupuncture for chronic pain: individual patient data metaanalysis. Arch Intern Med 172(19): 1444-1453.

7. Hinman RS, McCrory P, Pirotta M, Relf I, Forbes A, et al. (2014) Acupuncture for chronic knee pain: a randomized clinical trial. JAMA 312(13): 1313-1322.
8. Witt C, Brinkhaus B, Jena S, Linde K, Streng A, et al. (2005) Acupuncture in patients with osteoarthritis of the knee: a randomised trial. Lancet 366(9480): 136-143.

9. Vas J, Perea Milla E, Méndez C, Sánchez Navarro C, León Rubio JM, et al. (2006) Efficacy and safety of acupuncture for chronic uncomplicated neck pain: a randomised controlled study. Pain 126(1-3): 245-255.

10. Li Q Shi G, Xu Q Wang J, Liu C, et al. (2013) Acupuncture effect and central autonomic regulation. Evid Based Complement Alternat Med 2013: 267959.

11. Li Q Shi G, Xu Q Wang J, Liu C, et al. (2013) Acupuncture effect and central autonomic regulation. Evid Based Complement Alternat Med 2013: 267959.

12. Cheng N, Van Hoof H, Bockx E, Hoogmartens MJ, Mulier JC, et al. (1982) The effects of electric currents on ATP generation, protein synthesis, and membrane transport in Rat Skin. Clin Orthop Relat Res (171): 264272 .

13. McMakin C (2004) Microcurrent therapy: a novel treatment method for chronic low back myofascial pain. Journal of Bodywork and Movement Therapies 8(2): 143-153.

14. Chevalier A, Armstrong K, Norwood Williams C, Gokal R (2016) DC electroacupuncture effects on scars and sutures of a patient with post concussion pain. Med Acupunct 28(4): 223-229.

15. Armstrong K, Gokal R, Chevalier A, Todorsky W, Lim M (2016) Microcurrent point stimulation applied to acupuncture points for the treatment of non-specific lower back pain. J Altern Complement Med 23(4): 295-299.

16. Armstrong K, Gokal R, Chevalier A, Todorsky W, Lim M (2017) Microcurrent point stimulation applied to lower back acupuncture points for the treatment of nonspecific neck pain. J Altern Complement Med 23(4): 295-299.

17. Armstrong K, Gokal R, Durant J, Todorsky T, Chevalier A, et al. (2017) Detailed autonomic nervous system analysis of microcurrent point stimulation applied to battlefield acupuncture protocol. Medical Acupuncture 29(2).

18. Chevalier A, Armstrong K, Gokal R (2017) Detailed heart rate variability, exercise tolerance, cortical and vas pain scale analysis of two forms of electro-therapy applied to a patient with chronic back neuropathic pain. J Cell Mol Biol 1: 001.

19. Gokal R, Armstrong K, Durant J, Todorsky W, Miller L (2017) The Successful Treatment of Chronic Pain Using Microcurrent Point Stimulation Applied to Scars. Int J Complement Alt Med 10(3): 00333. 
20. http://www.accessdata.fda.gov/cdrh_docs/pdf13/K133789.pdf

21. Armstrong K (2016) Electrotherapy Exposed. Rehab Management, USA.

22. Krebs EE, Carey TS, Weinberger M (2007) Accuracy of the pain numeric rating scale as a screening test in primary care. J Gen Intern Med 22(10): 1453-1458.

23. Williamson A, Hoggart B (2005) Pain: a review of three commonly used pain rating scales. J Clin Nurs 14(7): 798-804.

24. Jensen MP, McFarland CA (1993) Increasing the reliability and validity of pain intensity measurement in chronic pain patients. Pain 55(2): 195-203.

25. Hawker GA, Mian S, Kendzerska T, French M (2011) Measures of Adult Pain Visual Analog Scale for Pain (VAS Pain), Numeric Rating
Scale for Pain (NRS Pain), McGill Pain Questionnaire (MPQ), ShortForm McGill Pain Questionnaire (SF-MPQ), Chronic Pain Grade Scale (CPGS), Short Form-36 Bodily Pain Scale (SF-36 BPS), and Measure of Intermittent and Constant Osteoarthritis Pain (ICOAP). Arthritis Care Res (Hoboken) 63 (Suppl 11): S240-S252.

26. Coan RM, Wong G, Coan PL (1982) The acupuncture treatment of neck pain: a randomized controlled study. Amer J Chin Med 9(4): 326-332.

27. Blossfeldt P (2016) Acupuncture for chronic neck pain -a cohort study in an NHS pain clinic. Acupuncture in Medicine 22(3): 146-151.

28. Chang R, Pomeranz B (1979) Electro-acupuncture-analgesia could be mediated by at least two pain-relieving mechanisms: endorphin and non-endorphin systems, Life Sci 25(23): 1957-1962.

This work is licensed under Creative

Commons Attribution 4.0 License

DOI: 10.19080/JYP.2018.04.555650 